\title{
Sport-related structural brain injury associated with arachnoid cysts: a systematic review and quantitative analysis
}

\author{
Scott L. Zuckerman, MD, ${ }^{1,2}$ Colin T. Prather, BA, ${ }^{1}$ Aaron M. Yengo-Kahn, BS, ${ }^{1}$ \\ Gary S. Solomon, PhD, ${ }^{1,2}$ Allen K. Sills, MD, ${ }^{1,2}$ and Christopher M. Bonfield, MD ${ }^{1,2}$ \\ ${ }^{1}$ Vanderbilt Sports Concussion Center, and 'Department of Neurological Surgery, Vanderbilt University School of Medicine, \\ Nashville, Tennessee
}

\begin{abstract}
OBJECTIVE Arachnoid cysts (ACs) are congenital lesions bordered by an arachnoid membrane. Researchers have postulated that individuals with an $\mathrm{AC}$ demonstrate a higher rate of structural brain injury after trauma. Given the potential neurological consequences of a structural brain injury requiring neurosurgical intervention, the authors sought to perform a systematic review of sport-related structural-brain injury associated with ACs with a corresponding quantitative analysis.

METHODS Titles and abstracts were searched systematically across the following databases: PubMed, Embase, CINAHL, and PsycINFO. The review was conducted in accordance with the Preferred Reporting Items for Systematic Reviews and Meta-Analyses (PRISMA) statement. Peer-reviewed case reports, case series, or observational studies that reported a structural brain injury due to a sport or recreational activity (hereafter referred to as sport-related) with an associated AC were included. Patients were excluded if they did not have an AC, suffered a concussion without structural brain injury, or sustained the injury during a non-sport-related activity (e.g., fall, motor vehicle collision). Descriptive statistical analysis and time to presentation data were summarized. Univariate logistic regression models to assess predictors of neurological deficit, open craniotomy, and cystoperitoneal shunt were completed.
\end{abstract}

RESULTS After an initial search of 994 original articles, 52 studies were found that reported 65 cases of sport-related structural brain injury associated with an AC. The median age at presentation was 16 years (range 4-75 years). Headache was the most common presenting symptom (98\%), followed by nausea and vomiting in $49 \%$. Thirteen patients (21\%) presented with a neurological deficit, most commonly hemiparesis. Open craniotomy was the most common form of treatment (49\%). Bur holes and cyst fenestration were performed in $29(45 \%)$ and 31 (48\%) patients, respectively. Seven patients (11\%) received a cystoperitoneal shunt. Four cases reported medical management only without any surgical intervention. No significant predictors were found for neurological deficit or open craniotomy. In the univariate model predicting the need for a cystoperitoneal shunt, the odds of receiving a shunt decreased as age increased $(p=0.004$, OR 0.62 [95\% Cl 0.45-0.86]) and with male sex ( $p=0.036$, OR 0.15 [95\% Cl 0.03-0.88]).

CONCLUSIONS This systematic review yielded 65 cases of sport-related structural brain injury associated with ACs. The majority of patients presented with chronic symptoms, and recovery was reported generally to be good. Although the review is subject to publication bias, the authors do not find at present that there is contraindication for patients with an AC to participate in sports, although parents and children should be counseled appropriately. Further studies are necessary to better evaluate AC characteristics that could pose a higher risk of adverse events after trauma.

http://thejns.org/doi/abs/10.3171/2016.1.FOCUS15608

KEY WORDS sports concussion; traumatic brain injury; arachnoid cyst; subdural hemorrhage; hygroma; return to play

$\mathrm{S}$ PORT-RELATED concussion (SRC) has emerged as a public health problem, affecting athletes of all ages and participation levels. ${ }^{11,35,43}$ While SRC by definition includes normal imaging results, a minority of sportrelated head injuries result in structural brain injury., 3,18 , 19,84,85 These cases are often neurosurgical emergencies and can result in permanent neurological deficit and/or death. Recent literature has postulated that athletes with arachnoid cysts (ACs) demonstrate a higher rate of structural brain injury after trauma, specifically subdural hematoma (SDH) or hygroma. ${ }^{37,44,79}$

ACs are congenital lesions bordered by an arachnoid

ABBREVIATIONS $\mathrm{AC}=$ arachnoid cyst; ICP = intracranial pressure; $\mathrm{IPH}=$ intraparenchymal hemorrhage; $I \mathrm{QR}=$ interquartile range; $\mathrm{PCS}=$ postconcussion syndrome; $\mathrm{SDH}=$ subdural hematoma; $\mathrm{SRC}=$ sport-related concussion. 
membrane. ${ }^{37,49}$ Cysts are filled with CSF, occur in $0.7 \%$ to $1.7 \%$ of the general population, ${ }^{56,76}$ and are found most commonly on the left side with a 3:1 male to female predilection. ${ }^{37,78}$ Several reviews have discussed the risk of SDH or hygroma associated with ACs after head trauma. ${ }^{37,44,79}$ The underlying mechanism for these structural injuries is unknown, but theories propose that 1) vessels without support of the cyst wall are prone to rupture, ${ }^{17,66} 2$ ) vessels within the wall can rupture due to decreased compliance, ${ }^{55}$ or 3) a slit-valve mechanism is created, leading to increased pressure within the $\mathrm{AC}$ and vessel rupture. ${ }^{64} \mathrm{~A}$ select few reports have addressed the issue of return to sport with an AC, with or without structural injury. ${ }^{21,44}$

Given the uncertainty surrounding structural brain injuries in athletes with an $\mathrm{AC}$ and the experiences at our own neurosurgical department and sports concussion center, we sought to review the literature in this area. The goals of this systematic review were to identify all cases of sport-related structural-brain injury associated with $\mathrm{ACs}$ and to perform a quantitative analysis in this unique patient population. Both objectives represent an overarching goal to better characterize, prevent complications, and counsel about return to play in athletes with an AC.

\section{Methods}

Published titles and abstracts in the English language were searched systematically across the following electronic databases: PubMed, Embase, CINAHL, and PsycINFO. The search terms included MeSH terms and keywords. Search words included the following: arachnoid cyst, sport-related concussion, subdural hematoma, subdural hygroma, sports injuries, and athletic injuries. The Preferred Reporting Items for Systematic Reviews and MetaAnalyse ${ }^{45}$ were adapted to review a heterogeneous collection of literature. A flow diagram of the included studies is seen in Fig. 1. Example search syntax from PubMed is noted below:

("Arachnoid Cysts"[Mesh] OR arachnoid cysts[tiab] OR arachnoid cyst[tiab]) AND ("Hematoma, Subdural"[Mesh] OR subdural hematoma[tiab] OR subdural hemorrhage[tiab] OR "subarachnoidhemorrhage"[tiab]OR "Lymphangioma, Cystic"[Mesh] OR hygroma[tiab] OR hygromas[tiab] OR "Hydrocephalus"[Mesh] OR hydrocephalus[tiab] OR “Athletic Injuries"[Mesh] OR athletic injuries[tiab] OR sports injuries[tiab] OR recreational injuries[tiab] OR "sport"[tiab] OR “sports"[tiab] OR “athletics"[tiab] OR "Craniocerebral Trauma"[Mesh] OR "head trauma"[tiab] OR "brain injury"[tiab] OR "brain injuries"[tiab] OR "mild traumatic brain injury"[tiab] OR "mTBI"[tiab] OR "traumatic brain injury" [tiab] OR "tbi”"[tiab] OR "injury"[tiab] OR "injuries"[tiab] OR "trauma"[tiab] OR "head injury"[tiab] OR "head injuries"[tiab] OR “concussion" [tiab] OR “concussions" [tiab] OR "complication" [tiab] OR “complications"[tiab])

Inclusion criteria consisted of the following: a case report, case series, or observational study of a patient with a structural brain injury due to a sport or recreational activity with an associated AC. Structural brain injury was defined most commonly as an acute or chronic SDH or subdural hygroma, in addition to less common injuries, such as epidural hematoma (EDH), subarachnoid hemorrhage (SAH), intraparenchymal hemorrhage (IPH), and skull fracture. "Sport-related" was defined according to definitions in earlier literature ${ }^{84}$ specifically any endeavor in which an individual was performing an athletic activity alone or in competition against an opposing person or team. Patients were excluded if they did not have an AC, suffered a concussion without structural brain injury, or sustained the injury during a non-sport-related activity (e.g., fall, motor vehicle collision). While the question of whether patients with an $\mathrm{AC}$ are at increased risk of structural brain injury is an important one, incidence data cannot be calculate from the current systematic review. Rather, the question of whether athletes with an AC can return to play will be addressed.

After the initial search was completed, as described in Fig. 1, a separate review of all references of included studies was completed to ensure no cases were missed. All references of included studies were systematically reviewed. Of the 980 references from included papers, 169 full-text sources were searched for eligibility. All but 3 were excluded for the following reasons: unrelated $(\mathrm{n}=$ $97)$, unspecified or not a sport-related trauma $(\mathrm{n}=8)$, or no trauma mentioned with AC complication $(n=61)$. The additional 3 sources were included in the final 52 articles.

\section{Statistical Analysis}

A descriptive statistical analysis was performed. Due to the limited sample size, a normal distribution was not assumed, and all data were considered to be nonparametric. Medians, interquartile ranges (IQR), and ranges were provided for continuous variables. Univariate logistic regression was performed to predict certain presentations or outcomes. A priori exposure variables included age, sex, days to presentation, presence of midline shift, and presence of a SDH. Multivariate analysis was not used due to limited sample and concern for an unstable model. Time to presentation data were represented with a Kaplan-Meier time to failure plot. ${ }^{29}$ All statistical analyses were performed in STATA (version 14, StataCorp LP).

\section{Results}

Our review yielded 52 studies reporting 65 cases of sport-related structural brain injury associated with an AC. The median year of publication was 2005, ranging from 1958 to 2015 (Fig. 2). The median age at presentation was 16 years (4-75 years) (Fig. 3), and 56 patients $(86 \%)$ were male. Age was not mentioned in 2 studies, whereas sex was mentioned in all.

\section{Presentation}

Presentation data are summarized in Table 1 . The median time from either injury or symptom onset to discovery of the structural injury was 25 days, ranging from 1 to 168 days. Of all 65 patients, symptom endorsement was mentioned in 61 (94\%) of studies. Headache was the most common symptom, presenting in all but 1 patient, followed by nausea and vomiting in $49 \%$. Thirteen patients (21\%) presented with a neurological deficit, most commonly hemiparesis. The range of sporting activities across 


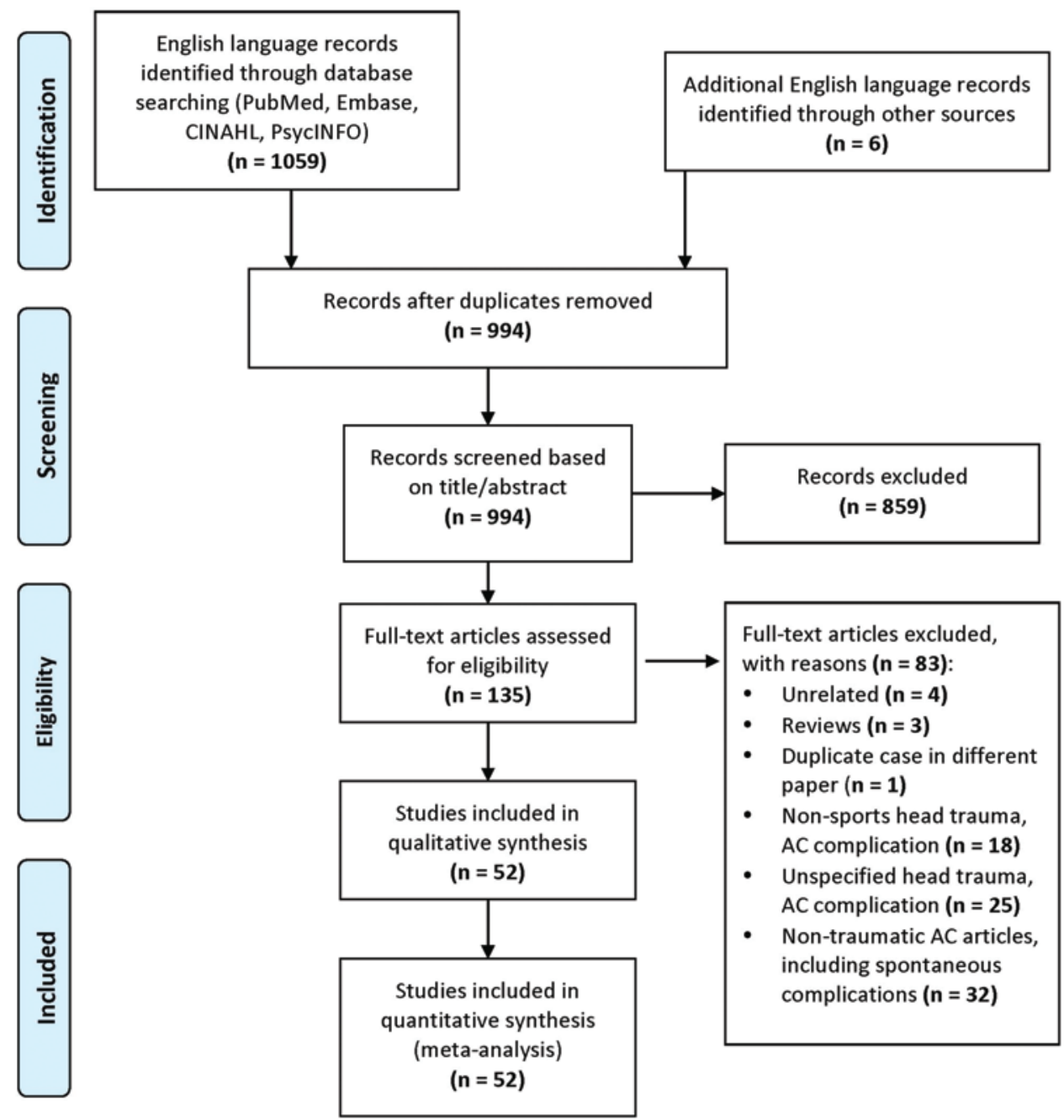

FIG. 1. Flow diagram representing systematic review process.

all 52 studies is detailed in Table 2. Team sports were involved in 28 cases (43\%).

\section{Imaging and Treatment}

Details regarding imaging and treatment are illustrated in Table 3. A CT scan and/or MRI of the head was obtained in all 65 cases. SDH was the most common structural injury (72\%) followed by hygroma (23\%), EDH (2\%), and IPH (2\%). The most common imaging finding of the structural abnormality (SDH or hygroma) on CT was an iso-/hypodense lesion signifying a chronic injury (76\%). Consistent with prior literature, $75 \%$ of patients harbored left-sided ACs. Due to the heterogeneous terminology and lack of complete CT/MRI studies, middle fossa and sylvian locations were combined and represented $98 \%$ of cases. Skull thinning adjacent to the cyst was seen in $60 \%$ of cases and often mentioned as a clue for AC presence when visualization was difficult, most often in the case of intracystic hemorrhage or an emergent, life-saving situation.

Four cases $(6 \%)$ reported medical management only without any surgical intervention; in 1 of these cases the family was offered surgery but refused. ${ }^{6}$ Two cases were hygromas that were followed with serial imaging and were noted to decrease over time, and one was an isolated 2.3$\mathrm{cm}$ IPH on the opposite side of the AC. Of the remaining 61 patients (94\%), open craniotomy alone was performed

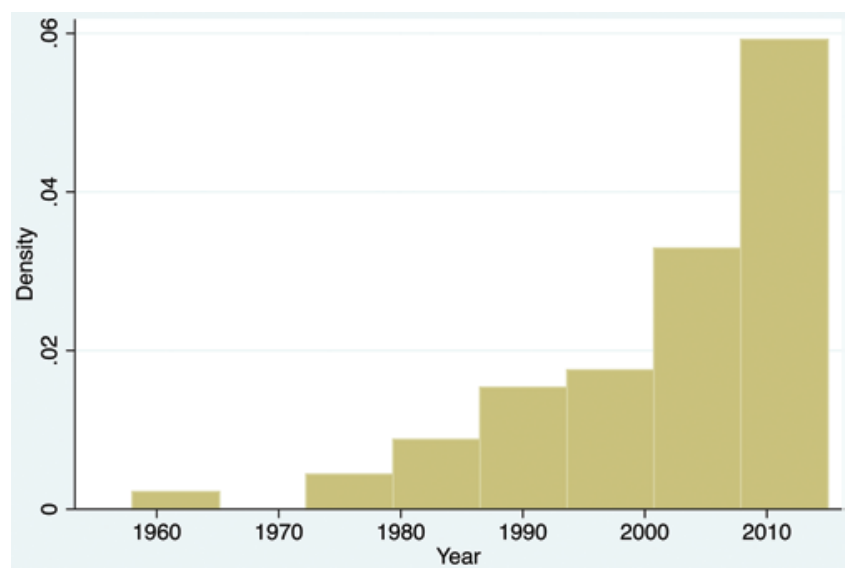

FIG. 2. Histogram showing year of publication. 


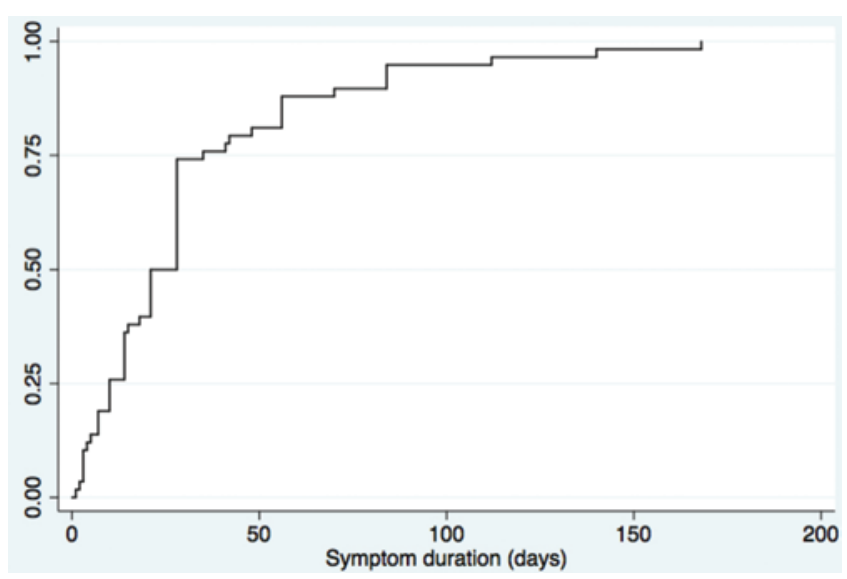

FIG. 3. Kaplan-Meier failure plot of time from injury or symptom onset to discovery of structural abnormality.

in 29 patients $(45 \%)$ and was the most common surgical procedure, followed by bur holes alone in 26 patients (41\%); 3 patients (5\%) underwent both. During the open craniotomy or bur hole, cyst fenestration was performed in 31 patients $(48 \%)$. Seven patients $(11 \%)$ received a cystoperitoneal shunt. Five patients (8\%) underwent more than 1 operation. An endoscope was used in 2 cases (3\%). ${ }^{24,75} \mathrm{~A}$ postoperative outcome was mentioned in 36 cases (55\%). Each of the 65 cases is summarized in Table 4.

Three univariate models were conducted in an attempt to predict 1) a neurological deficit, 2) need for open craniotomy, and 3) need for a cystoperitoneal shunt (Table 5). The predictive factors in each model were determined a priori and included age, sex, days to presentation, midline shift, and presence of an SDH. No significant predictors were found for neurological deficit or open craniotomy. In the model predicting the need for a cystoperitoneal shunt, the odds of receiving a shunt decreased as age increased $(\mathrm{p}=0.004$, OR 0.62 [95\% CI 0.45-0.86]) and with male sex ( $\mathrm{p}=0.036$, OR 0.15 [95\% CI 0.03-0.88]).

\section{Discussion}

While posttraumatic SRC in general has been well studied, less is known about structural brain injuries in sports. ACs are congenital malformations with the potential to hemorrhage after relatively minor head injury. The goal of this systematic review was to summarize all cases of sport-related structural brain injury associated with $\mathrm{ACs}$ and to provide a quantitative analysis. A total of 65 cases were found across 52 studies, dating back to 1958 . This review represents the largest of sport-related structural brain injury associated with ACs to date. The clinical implications of our findings are discussed below.

\section{Presentation}

An overwhelming majority of cases (84\%) were chronic, with a median time to presentation of nearly 4 weeks. Many cases had multiple presentations to clinic for lingering symptoms, and only on the second or third visit was imaging performed. However, this trend is subject to pub-
TABLE 1. Study and demographic variables

\begin{tabular}{lc}
\hline \multicolumn{1}{c}{ Characteristic } & Value \\
\hline Study type, no. (\%) & $52(100)$ \\
Case report & $30(58)$ \\
Case series & $21(40)$ \\
Case-control & $1(2)$ \\
\hline Yr of publication, median (IQR) & $2005(1997-2013)$ \\
\hline Total cases, no. (\%) & $65(100)$ \\
Pediatric & $41(63)$ \\
Adult & $24(37)$ \\
\hline Age in yrs, median (IQR) & $16(12-21)$ \\
\hline Male, no. (\%) & $56(86)$ \\
\hline Time to presentation & $58(100)$ \\
Days to presentation, median (IQR) & $25(10-35)$ \\
Acute $<7$ days, $n$ (\%) & $9(16)$ \\
Chronic $\geq 7$ days, $n(\%)$ & $49(84)$ \\
Symptoms, no (\%) & $61(100)$ \\
Headache & $60(98)$ \\
Nausea/vomiting & $30(49)$ \\
Dizziness & $6(5)$ \\
Diplopia & $8(13)$ \\
Other & $4(7)$ \\
Neurological deficit, no. (\%) & $61(100)$ \\
Extremity weakness & $4(7)$ \\
Numbness & $3(5)$ \\
Decreased responsiveness & $2(3)$ \\
CN VI palsy & $2(3)$ \\
Facial weakness & $2(3)$ \\
\hline
\end{tabular}

$\mathrm{CN}=$ cranial nerve.

lication bias, as a delayed SDH due to sports injury is more novel than the more common acute SDH. In addition, it is evident from our review that sport-related structural brain injury associated with ACs is not only a problem in team sports. Sporting activities ranged from martial arts to winter sports (e.g., skiing, snowboarding), and these nonteam sports accounted for the majority of cases. Furthermore, it is important to realize that athletes engaged in noncontact sports have also been reported to have AC hemorrhage, necessitating a high level of attention to patients regardless of the contact level of sport played.

How these patients present is perhaps most interesting when differentiating structural brain injury from postconcussion syndrome (PCS). PCS is a well-studied entity across many populations after general trauma, military blast injury, and SRC. ${ }^{25,39,67,69}$ Tator et al.$^{69}$ comprehensively described the phenotype of PCS across 138 athletes, where most patients were younger than 30 years with an average of 7.6 symptoms for a median of 6 months. As both populations have symptom duration of weeks to months, differentiating between a recovering PCS patient with no structural injury versus one with an AC associated $\mathrm{SDH}$ or hygroma becomes challenging.

Based on our review, a persistent headache was present in $98 \%$ of patients, nausea and/or vomiting in nearly half, and diplopia in 13\%. This symptom constellation represents a clear picture of increased intracranial pres- 
TABLE 2. Sporting activities and cases in the 52 included studies

\begin{tabular}{|c|c|c|}
\hline Sport & Authors \& Year & $\begin{array}{l}\text { No. of } \\
\text { Cases }(\%)^{*}\end{array}$ \\
\hline Soccer† & $\begin{array}{l}\text { Oliver, 1958; Maeda et al., 1993; Kawanishi et al., } 1999 \text { ( } 2 \text { cases); Chillala et al., 2001; Prabhu \& Bailes, 2002; } \\
\text { Demetriades et al., 2004; Offiah et al., 2006; Domenicucci et al., 2009; Zeng et al., 2011; Işik et al., 2011; } \\
\text { Maher et al., 2013; Edmondson et al., 2014; Takizawa et al., } 2015\end{array}$ & $14(22)$ \\
\hline Bicycle & $\begin{array}{l}\text { Kulali \& von Wild, 1989; Rogers et al., 1990; Donaldson et al., 2000; Pillai et al., 2009; Domenicucci et al., } \\
\text { 2009; Seddighi et al., 2012; Blereau \& Haley, 2013; Raveenthiran \& Reshma 2014; Takizawa et al., } 2015\end{array}$ & $9(14)$ \\
\hline Football $†$ & $\begin{array}{l}\text { Vigil et al., 1998; Donaldson et al., 2000; Gelabert-González et al., 2002; Bristol et al., 2007; Maher et al., } \\
\text { 2013; Cress et al., 2013; Pascoe et al., } 2015\end{array}$ & $7(11)$ \\
\hline Martial arts & $\begin{array}{l}\text { Weinberg \& Flom, 1973; Yokoyama et al., 1989; Türkoğlu et al., 2008; Kertmen et al., 2012; Takizawa et al., } \\
2015\end{array}$ & $5(8)$ \\
\hline Swimming/water sports & LaCour et al., 1978; Cullis \& Gilroy, 1983; Rogers et al., 1990; Mori et al., 1995; Zhang et al., 2007 & $5(8)$ \\
\hline Basketball $\dagger$ & Rogers et al., 1990; Tsuzuki et al., 2003; Chen et al., 2005; Hou et al., 2014 & $4(6)$ \\
\hline Physical/weight training & Ochi et al., 1996; Mori et al., 2002; Park et al., 2013 & $3(5)$ \\
\hline Ski/snowboarding & Takizawa et al., 2015 & $2(3)$ \\
\hline Boxing & Robles \& Hernandez, 2006 & $1(2)$ \\
\hline Cricket & Gupta et al., 2004 & $1(2)$ \\
\hline Dancing & McNeil et al., 1987 & $1(2)$ \\
\hline Equestrian & Page et al., 1987 & $1(2)$ \\
\hline Hockey† & Ellis et al., 2015 & $1(2)$ \\
\hline Rollerblading & Albuquerque \& Giannotta, 1997 & $1(2)$ \\
\hline Rollercoaster & Huang, 2003 & $1(2)$ \\
\hline Rugby† & Varma et al., 1981 & $1(2)$ \\
\hline Skateboarding & Varma et al., 1981 & $1(2)$ \\
\hline Volleyball† & Hamada et al., 2010 & $1(2)$ \\
\hline Sport not specified & $\begin{array}{l}\text { Ulmer et al., 2002; Pretorius \& McAuley, 2005; Tsitsopoulos et al., 2008; Zeng et al., 2011; Zheng et al., } 2013 \\
\text { ( } 2 \text { cases) }\end{array}$ & $6(8)$ \\
\hline Total & & 65 \\
\hline
\end{tabular}

* Due to rounding, total $\%$ is greater than $100 \%$.

$\dagger$ Denotes team sport.

sure (ICP). In the previously mentioned study of PCS, ${ }^{69}$ headache was also endorsed by $90 \%$ of patients, followed by memory disorders (58\%) and concentration problems (57\%); nausea was endorsed by $37 \%$ of athletes and vomiting in only $3 \%$. The issue of when to order imaging after $\mathrm{SRC}$ is a controversial one, as imaging in the chronic phase of PCS can be low yield and costly. ${ }^{16,46}$ However, imaging was potentially lifesaving in the reviewed population of 65 patients. Thus, based on the present systematic review, we recommend imaging when persistent signs and symptoms of increased ICP are present. ${ }^{32,36}$ Based on a median time to presentation of 25 days, imaging can be pursued at any time, but there may be a higher yield weeks after injury. Differentiating between symptoms of increased ICP versus PCS is much easier written than accomplished, but a detailed temporal history, fundoscopic examination checking for papilledema, and neuropsychological testing may aid in this differentiation. Furthermore, 13 patients $(21 \%)$ presented with an objective neurological deficit such as hemiparesis or facial weakness, which is never seen in PCS. Imaging should promptly be performed in all patients who demonstrate a fixed neurological deficit on clinical examination.

\section{Imaging and Treatment}

Most structural injuries were seen as isodense or hypodense lesions, signifying the chronic nature of the subdural and/or intracystic hematoma. To our surprise, the AC location was difficult to standardize across many of the studies reviewed. The well-known Galassi classification quantifies ACs based on extent of middle fossa involvement and compression of adjacent neural structures. ${ }^{20}$ While some articles mentioned the Galassi type, most did not. Whereas some authors labeled an $\mathrm{AC}$ as middle fossa, others would call a similar lesion temporal. Thus, we were unable to delineate the AC location given the heterogeneous nomenclature used. We emphasize the need for future work of AC associated structural sportrelated brain injury to standardize cyst location. Also, the size of the AC was not recorded in most studies, likely due to hemorrhage obscuring the ability to fully visualize the entire cyst. If possible, future studies should also include $\mathrm{AC}$ size details, as the relationship between $\mathrm{AC}$ size and hemorrhage is also unknown.

Open craniotomy was the most common mode of surgical treatment, and nearly half of all cases mentioned cyst fenestration. Fenestration to the basal cisterns was 
TABLE 3. Radiographic, treatment, and outcome variables

\begin{tabular}{cc}
\hline \multicolumn{1}{c}{ Characteristic } & Value \\
\hline Injury density, no. (\%) & $54(100)$ \\
Hyperdense & $13(24)$ \\
Iso-/hypodense & $41(76)$ \\
\hline Side, no. (\%) & $64(100)$ \\
Left & $48(75)$ \\
Right & $15(23)$ \\
Bilateral & $1(2)$ \\
\hline Location, no. (\%) & $64(100)$ \\
Middle fossa/sylvian & $63(98)$ \\
Interhemispheric & $1(2)$ \\
\hline Skull thinning, no. (\%) & $24 / 40(60)$ \\
\hline Structural Injury, no. (\%) & $64(100)$ \\
SDH & $47(73)$ \\
Hygroma & $15(23)$ \\
EDH & $1(2)$ \\
IPH & $1(2)$ \\
\hline Midline shift, no. (\%) & $39 / 49(80)$ \\
\hline Treatment, no. (\%) & $65(100)$ \\
Bur hole & $26(41)$ \\
Open craniotomy & $29(45)$ \\
Bur hole \& open craniotomy & $3(5)$ \\
Cyst fenestration & $31(48)$ \\
Cystoperitoneal shunt* & $7(11)$ \\
Surgery unspecified & $2(3)$ \\
No surgery & $4(6)$ \\
\hline Outcome mentioned, no. (\%) & $36(55)$ \\
\hline Return to play mentioned, no. (\%) & $4(6)$ \\
\hline * of note, 1 patient's only treatment was a cystoperitoneal shunt without bur \\
hole or open craniotomy. & \\
\hline &
\end{tabular}

mentioned in select cases, with intraoperative visualization of the circle of Willis. ${ }^{57}$ Therefore, surgeons should be aware that complex dissections may be required in cases in which bur hole treatment alone is insufficient. Due to the paucity of outcomes, there are not enough data to recommend fenestration, but it certainly appears that in large enough ACs, fenestration should be done whenever possible. Moreover, an endoscope was used in 2 studies, which provides a reasonable, less invasive option. $.^{24,75} \mathrm{An}-$ other option for treatment that bears mention is acetazolamide to decrease CSF production, and in select cases has obviated the need for surgical treatment. ${ }^{8,38,41}$ Cystoperitoneal shunts were placed in 7 patients, and our model predicted that younger age was significantly associated with increased odds of a cystoperitoneal shunt placement, in addition to female sex.

In some cases, the $\mathrm{AC}$ was not realized until after the initial decompression, and a second operation was needed for definitive treatment. ${ }^{26,30,47}$ Though clearly evident in some cases, the cyst may be filled with acute or chronic blood products, making it difficult to see. Skull thinning was noted in $60 \%$ of cases, and can be a subtle, yet important finding when a SDH is seen after a sports injury or low energy trauma.

\section{Future Directions}

A more common problem than the case of a sport-related structural injury associated with ACs is the initial clinical discussion surrounding involvement in sports after the incidental finding of an asymptomatic AC. ${ }^{21}$ Unfortunately, minimal information is available in the literature to guide these decisions about sports participation with an AC. A postoperative outcome was mentioned in over half of the studies, often in a limited fashion, and all instances mentioned good or uneventful outcomes. Furthermore, only $3 \%$ of studies mentioned return to sport or activity. With the current estimate of asymptomatic ACs at $0.7 \%-$ $1.7 \%$ of the population, it can be extrapolated that on an American football field comprising approximately 90 athletes from both teams, it would not be uncommon for at least 1 player to have an asymptomatic AC. The issue of involvement in sports with an AC, with or without structural injury, is an important one as surveillance imaging becomes increasingly used.

One report of a 32-year-old professional football player described an asymptomatic AC found on imaging for cervical radicular symptoms. ${ }^{21}$ The cyst was $7.5 \mathrm{~cm}$ in its greatest dimension and located in the left sylvian fissure. The player was cleared to play football and had no neurological sequelae, with normal findings on postseason MRI. Gamradt et al. ${ }^{21}$ postulated 2 questions: does the $\mathrm{AC}$ place the player at increased risk for a SDH or hygroma, and what are the sequelae of that structural injury? Anecdotally, the authors hypothesized the presence of an AC did confer a slightly higher risk of hemorrhage due to the cyst incompressibility and associated calvaria thinning, although the exact magnitude of the risk could not be quantified. Miele et al. ${ }^{44}$ echoed this sentiment, stating that although an AC may hold an increased risk of hemorrhage, it is not an absolute contraindication to participation in contact sports, and patients and family members should be counseled of these risks. Unfortunately, similar to other analyses, we cannot calculate incidence rates of hemorrhage, nor are we able to quantify risk.

To the second question, our systematic review yielded a somewhat incomplete answer. Of the $55 \%$ of studies that mentioned an outcome, all endorsed an uneventful recovery. However, most studies devoted only one sentence to the postoperative course. Thus, based on the limited information provided, we can say that in those studies that reported outcomes, all patients recovered well at the gross neurological level. According to the current evidence base, we do not feel that there is a clear contraindication for patients with an $\mathrm{AC}$ to participate in sports, although parents and children should be counseled of the perceived risks. Similar questions surround patients with Chiari malformations, which, when asymptomatic, have been viewed more as a relative than absolute contraindication. ${ }^{5,44}$ However, absolute contraindication is recommended in patients who are symptomatic, have brainstem compression, or harbor a syrinx.$^{44}$ Although outside the scope of this systematic review, equally important are return to play issues in athletes with a ventriculoperitoneal shunt, epilepsy, or prior craniotomy. ${ }^{44}$

\section{Limitations}

Although our study represents a comprehensive re- 
TABLE 4. Itemized 65 cases

\begin{tabular}{|c|c|c|c|c|c|c|c|}
\hline $\begin{array}{l}\text { Case } \\
\text { No. }\end{array}$ & Authors \& Year & $\begin{array}{c}\text { Age } \\
\text { (yrs), } \\
\text { Sex }\end{array}$ & Sport & Pathology & $\begin{array}{l}\text { Midline } \\
\text { Shift }\end{array}$ & Treatment & Outcome \\
\hline 1 & Takizawa et al., 2015 & $13, M$ & Bicycle & $\mathrm{SDH}$ & NR & Bur hole & NR \\
\hline 2 & Takizawa et al., 2015 & $31, M$ & Martial arts & $\mathrm{SDH}$ & NR & Bur hole & NR \\
\hline 3 & Takizawa et al., 2015 & $35, F$ & Ski/snowboarding & $\mathrm{SDH}$ & NR & Bur hole & NR \\
\hline 4 & Takizawa et al., 2015 & $32, M$ & Ski/snowboarding & $\mathrm{SDH}$ & NR & Open craniotomy & NR \\
\hline 5 & Takizawa et al., 2015 & $15, M$ & Soccer & $\mathrm{SDH}$ & NR & Open craniotomy & NR \\
\hline 6 & Pascoe et al., 2015 & $43, M$ & Football & $\mathrm{SDH}$ & Yes & Open craniotomy & NR \\
\hline 7 & Ellis et al., 2015 & $11, \mathrm{M}$ & Hockey & $\mathrm{IPH}$ & No & No surgery & $\begin{array}{l}\text { Good; no return } \\
\text { to sport }\end{array}$ \\
\hline 8 & $\begin{array}{l}\text { Raveenthiran \& Reshma, } \\
2014\end{array}$ & $4, M$ & Bicycle & Hygroma & No & Cystoperitoneal shunt & Good \\
\hline 9 & Hou et al., 2014 & $17, \mathrm{M}$ & Basketball & $\mathrm{SDH}$ & Yes & Bur hole & Good \\
\hline 10 & Edmondson et al., 2014 & $14, M$ & Soccer & $\mathrm{SDH}$ & Yes & Bur hole & Good \\
\hline 11 & Zheng et al., 2013 & $19, M$ & NR & $\mathrm{SDH}$ & NR & Bur hole & NR \\
\hline 12 & Zheng et al., 2013 & $16, M$ & NR & $\mathrm{SDH}$ & NR & Bur hole & NR \\
\hline 13 & Park et al., 2013 & $75, M$ & Physical/weight training & $\mathrm{SDH}$ & No & Bur hole & Good \\
\hline 14 & Maher et al., 2013 & 16, M & Football & Hygroma & No & No surgery & Good \\
\hline 15 & Maher et al., 2013 & $12, \mathrm{~F}$ & Soccer & Hygroma & No & No surgery & Good \\
\hline 16 & Cress et al., 2013 & NR, M & Football & SDH or hygroma & NR & Open craniotomy & NR \\
\hline 17 & Blereau \& Haley, 2013 & $7, \mathrm{~F}$ & Bicycle & $\mathrm{SDH}$ & Yes & Bur hole; cystoperitoneal shunt & Good \\
\hline 18 & Seddighi et al., 2012 & $23, M$ & Bicycle & $\mathrm{EDH}$ & Yes & Open craniotomy & NR \\
\hline 19 & Kertmen et al., 2012 & $12, M$ & Martial arts & $\mathrm{SDH}$ & Yes & Bur hole & Good \\
\hline 20 & Zeng et al., 2011 & $16, M$ & Soccer & $\mathrm{SDH}$ & Yes & Bur hole & Good \\
\hline 21 & Zeng et al., 2011 & $14, M$ & NR & $\mathrm{SDH}$ & Yes & Open craniotomy & Good \\
\hline 22 & Işik et al., 2011 & 13, M & Soccer & $\mathrm{SDH}$ & Yes & Bur hole & Good \\
\hline 23 & Hamada et al., 2010 & $15, M$ & Volleyball & $\mathrm{SDH}$ & No & Open craniotomy & NR \\
\hline 24 & Pillai et al., 2009 & $23, M$ & Bicycle & $\mathrm{SDH}$ & Yes & Bur hole; open craniotomy & Good \\
\hline 25 & Domenicucci et al., 2009 & $41, M$ & Bicycle & $\mathrm{SDH}$ & NR & Burr hole & Good \\
\hline 26 & Domenicucci et al., 2009 & $7, \mathrm{M}$ & Soccer & $\mathrm{SDH}$ & NR & Bur hole & Good \\
\hline 27 & Türkoğlu et al., 2008 & $25, M$ & Martial arts & $\mathrm{SDH}$ & Yes & Bur hole & Good \\
\hline 28 & Tsitsopoulos et al., 2008 & $15, M$ & NR & $\mathrm{SDH}$ & Yes & Open craniotomy & Good \\
\hline 29 & Zhang et al., 2007 & $21, M$ & Swimming/water sports & $\mathrm{SDH}$ & Yes & Open craniotomy & Good \\
\hline 30 & Bristol et al., 2007 & $17, M$ & Football & Hygroma & No & Open craniotomy & Good \\
\hline 31 & Robles \& Hernandez, 2006 & $20, M$ & Boxing & $\mathrm{SDH}$ & Yes & Open craniotomy & Good \\
\hline 32 & Offiah et al., 2006 & $8, M$ & Soccer & Hygroma & Yes & $\begin{array}{l}\text { Open craniotomy; cystoperito- } \\
\text { neal shunt }\end{array}$ & Good \\
\hline 33 & Pretorius \& McAuley, 2005 & $11, \mathrm{M}$ & NR & $\mathrm{SDH}$ & Yes & Open craniotomy & NR \\
\hline 34 & Chen et al., 2005 & $20, M$ & Basketball & $\mathrm{SDH}$ & Yes & No surgery & NR \\
\hline 35 & Demetriades et al., 2004 & $24, M$ & Soccer & $\mathrm{SDH}$ & Yes & Bur hole & Good \\
\hline 36 & Gupta et al., 2004 & $22, M$ & Cricket & Hygroma & No & Bur hole & NR \\
\hline 37 & Tsuzuki et al., 2003 & $16, F$ & Basketball & $\mathrm{SDH}$ & Yes & Bur hole & Good \\
\hline 38 & Huang, 2003 & $33, F$ & Rollercoaster & Hygroma & No & Bur hole & NR \\
\hline 39 & Ulmer et al., 2002 & $44, \mathrm{M}$ & NR & $\mathrm{SDH}$ & Yes & Open craniotomy & Good \\
\hline 40 & Prabhu \& Bailes, 2002 & $16, F$ & Soccer & $\mathrm{SDH}$ & Yes & Open craniotomy & NR \\
\hline 41 & Mori et al., 2002 & $14, M$ & Physical/weight training & SDH & Yes & Bur hole & Good \\
\hline 42 & Gelabert-González, 2002 & $13, M$ & Football & Hygroma & Yes & Open craniotomy & Good \\
\hline
\end{tabular}


» CONTINUED FROM PAGE 7

TABLE 4. Itemized 65 cases

\begin{tabular}{|c|c|c|c|c|c|c|c|}
\hline $\begin{array}{l}\text { Case } \\
\text { No. }\end{array}$ & Authors \& Year & $\begin{array}{c}\text { Age } \\
\text { (yrs), } \\
\text { Sex }\end{array}$ & Sport & Pathology & $\begin{array}{l}\text { Midline } \\
\text { Shift }\end{array}$ & Treatment & Outcome \\
\hline 43 & Chillala et al., 2001 & $21, M$ & Soccer & $\mathrm{SDH}$ & No & Surgery, unspecified & Good \\
\hline 44 & Donaldson et al., 2000 & $5, \mathrm{M}$ & Bicycle & Hygroma & NR & Bur hole; open craniotomy & Good \\
\hline 45 & Donaldson et al., 2000 & $14, \mathrm{M}$ & Football & Hygroma & NR & Open craniotomy & $\begin{array}{l}\text { Good; returned } \\
\text { to football }\end{array}$ \\
\hline 46 & Kawanishi et al., 1999 & $14, \mathrm{M}$ & Soccer & $\mathrm{SDH}$ & Yes & Bur hole & NR \\
\hline 47 & Kawanishi et al., 1999 & $11, \mathrm{M}$ & Soccer & SDH & Yes & Bur hole & NR \\
\hline 48 & Vigil et al., 1998 & $16, M$ & Football & Hygroma & Yes & Bur hole & $\begin{array}{l}\text { Good; returned } \\
\text { to football }\end{array}$ \\
\hline 49 & $\begin{array}{l}\text { Albuquerque \& Giannotta, } \\
1997\end{array}$ & $6, M$ & Rollerblading & Hygroma & Yes & $\begin{array}{l}\text { Open craniotomy; cysto-perito- } \\
\text { neal shunt }\end{array}$ & Good \\
\hline 50 & Ochi et al., 1996 & $12, \mathrm{M}$ & Physical/weight training & SDH & Yes & Surgery, unspecified & NR \\
\hline 51 & Mori et al., 1995 & $29, \mathrm{M}$ & Swimming/water sports & $\mathrm{SDH}$ & Yes & Bur hole & NR \\
\hline 52 & Maeda et al., 1993 & $14, \mathrm{M}$ & Soccer & $\mathrm{SDH}$ & Yes & Open craniotomy & NR \\
\hline 53 & Rogers et al., 1990 & $10, \mathrm{~F}$ & Basketball & $\mathrm{SDH}$ & NR & Bur hole; cystoperitoneal shunt & NR \\
\hline 54 & Rogers et al., 1990 & $11, \mathrm{M}$ & Bicycle & $\mathrm{SDH}$ & NR & Bur hole & NR \\
\hline 55 & Rogers et al., 1990 & $12, \mathrm{~F}$ & Swimming/water sports & $\mathrm{SDH}$ & NR & $\begin{array}{l}\text { Open craniotomy; cystoperito- } \\
\text { neal shunt }\end{array}$ & NR \\
\hline 56 & Kulali \& von Wild, 1989 & $\mathrm{NR}, \mathrm{M}$ & Bicycle & Hygroma & Yes & $\begin{array}{l}\text { Open craniotomy; cystoperito- } \\
\text { neal shunt }\end{array}$ & NR \\
\hline 57 & Yokoyama et al., 1989 & $17, \mathrm{M}$ & Martial arts & SDH & Yes & Open craniotomy & NR \\
\hline 58 & Page et al., 1987 & $57, \mathrm{M}$ & Equestrian & $\mathrm{SDH}$ & Yes & Open craniotomy & NR \\
\hline 59 & McNeil et al., 1987 & $17, M$ & Dancing & $\mathrm{SDH}$ & Yes & Open craniotomy & $\begin{array}{l}\text { Good; no return } \\
\text { to dancing }\end{array}$ \\
\hline 60 & Cullis \& Gilroy, 1983 & $11, \mathrm{M}$ & Swimming/water sports & Hygroma & Yes & Open craniotomy & NR \\
\hline 61 & Varma et al., 1981 & $17, \mathrm{M}$ & Rugby & $\mathrm{SDH}$ & NR & Open craniotomy & Good \\
\hline 62 & Varma et al., 1981 & $13, \mathrm{M}$ & Skateboarding & Hygroma & Yes & Open craniotomy & Good \\
\hline 63 & LaCour et al., 1978 & $13, \mathrm{~F}$ & Swimming/water sports & $\mathrm{SDH}$ & Yes & Open craniotomy & NR \\
\hline 64 & Weinberg \& Flom, 1973 & $20, M$ & Martial arts & $\mathrm{SDH}$ & Yes & Bur hole; open craniotomy & NR \\
\hline 65 & Oliver, 1958 & $21, M$ & Soccer & SDH & Yes & Open craniotomy & Good \\
\hline
\end{tabular}

$\mathrm{NR}=$ not reported.

view, biases of a retrospective review exist. First, publication bias may be present in 3 major forms: the predilection to publish on 1) good outcomes, 2) patients who underwent surgery, and 3) patients with delayed clinical findings. The push for publication may be a reason that all but 3 of the 52 studies reviewed described operative treatment, when in reality nonoperative treatment may occur more commonly than is presented. Furthermore, delayed (as opposed to acute) clinical findings are more likely to be published, as these tend to be more novel and reportable. Second, sport-specific data were sparse, and in some studies only a remote history of sport was mentioned, sometimes without a distinct impact or collision. Several studies reported unspecified athletic events, which could represent a wide range of sporting activities. Thus, we had to rely on the limited history provided. Third, operative details were not recorded uniformly across authors, and some studies lacked important detail in dictating operative treatment.

\section{Conclusions}

Sport-related structural brain injury associated with an $\mathrm{AC}$ is a rare occurrence. The current systematic review informs us that these injuries are often chronic, with median time to presentation of 25 days, and most commonly presenting with headache and nausea/vomiting. Injuries occur in both team/nonteam and contact/noncontact sports, and the majority are treated with open craniotomy or bur hole. Outcomes were good in all studies that mentioned one.

That said, substantial information is needed to better treat and avoid these serious injuries. Cyst location was not standardized in most studies, nor was cyst size mentioned, making the relationship between cyst size and risk of rupture impossible to ascertain. Furthermore, significant gaps in postoperative outcomes and return to sport were found. According to the current evidence base, we do not feel that there is a clear contraindication to participate in sports in patients with an $\mathrm{AC}$, although parents and children should 
TABLE 5. Univariate logistic regression analysis showing predictors of presentation and treatment

\begin{tabular}{llll}
\hline \multicolumn{1}{c}{ Predictive Factor } & OR & $95 \% \mathrm{Cl}$ & $\mathrm{p}$ Value \\
\hline Neurological deficit & & & \\
\hline Age & 1.00 & $(0.95-1.05)$ & 0.866 \\
\hline Sex & 0.92 & $(0.17-5.05)$ & 0.920 \\
\hline Days to presentation & 0.99 & $(0.97-1.02)$ & 0.608 \\
\hline Midline shift & 1.09 & $(0.19-6.19)$ & 0.926 \\
\hline SDH & 1.33 & $(0.20-2.30)$ & 0.532 \\
\hline Craniotomy & & & \\
\hline Age & 1.00 & $(0.96-1.04)$ & 0.819 \\
\hline Sex & 2.42 & $(0.55-10.70)$ & 0.245 \\
\hline Days to presentation & 1.00 & $(0.99-1.02)$ & 0.760 \\
\hline Midline shift & 4.31 & $(0.77-24.15)$ & 0.096 \\
\hline SDH & 0.53 & $(0.16-1.69)$ & 0.280 \\
\hline Cystoperitoneal shunt & & & \\
\hline Age & 0.59 & $(0.42-0.85)$ & 0.004 \\
\hline Sex & 0.15 & $(0.03-0.88)$ & 0.036 \\
\hline Days to presentation & 0.97 & $(0.90-1.04)$ & 0.321 \\
\hline Midline shift & 0.97 & $(0.09-9.90)$ & 0.979 \\
\hline SDH & 0.25 & $(0.05-1.28)$ & 0.096 \\
\hline
\end{tabular}

be counseled appropriately. Further studies are necessary to better evaluate AC characteristics that could pose a higher risk of adverse events after trauma.

\section{References}

1. Albuquerque FC, Giannotta SL: Arachnoid cyst rupture producing subdural hygroma and intracranial hypertension: case reports. Neurosurgery 41:951-956, 1997

2. Blereau RP, Haley TJ: Arachnoid cyst. Consultant 53:540541, 2013

3. Boden BP, Tacchetti RL, Cantu RC, Knowles SB, Mueller FO: Catastrophic head injuries in high school and college football players. Am J Sports Med 35:1075-1081, 2007

4. Bristol RE, Albuquerque FC, McDougall C, Spetzler RF: Arachnoid cysts: spontaneous resolution distinct from traumatic rupture. Case report. Neurosurg Focus 22(2):E2, 2007

5. Callaway GH, O'Brien SJ, Tehrany AM: Chiari I malformation and spinal cord injury: cause for concern in contact athletes? Med Sci Sports Exerc 28:1218-1220, 1996

6. Chen HY, Li YS, Chen CH, Shen WC, Ying KS: Concomitant traumatic spinal hematoma and hemorrhage from intracranial arachnoid cyst following minor injury. Zhonghua Fang She Xue Za Zhi 30:173-177, 2005

7. Chillala S, Read C, Evans PA: An unusual case of subdural haematoma presenting to the accident and emergency department. Emerg Med J 18:308-309, 2001

8. Choong CT, Lee SH: Subdural hygroma in association with middle fossa arachnoid cyst: acetazolamide therapy. Brain Dev 20:319-322, 1998

9. Cress M, Kestle JR, Holubkov R, Riva-Cambrin J: Risk factors for pediatric arachnoid cyst rupture/hemorrhage: a casecontrol study. Neurosurgery 72:716-722, 2013

10. Cullis PA, Gilroy J: Arachnoid cyst with rupture into the subdural space. J Neurol Neurosurg Psychiatry 46:454-456, 1983

11. Daneshvar DH, Nowinski CJ, McKee AC, Cantu RC: The epidemiology of sport-related concussion. Clin Sports Med 30:1-17, vii, 2011

12. Demetriades AK, McEvoy AW, Kitchen ND: Subdural haematoma associated with an arachnoid cyst after repetitive minor heading injury in ball games. Br J Sports Med 38:E8, 2004

13. Domenicucci M, Russo N, Giugni E, Pierallini A: Relationship between supratentorial arachnoid cyst and chronic subdural hematoma: neuroradiological evidence and surgical treatment. J Neurosurg 110:1250-1255, 2009

14. Donaldson JW, Edwards-Brown M, Luerssen TG: Arachnoid cyst rupture with concurrent subdural hygroma. Pediatr Neurosurg 32:137-139, 2000

15. Edmondson L, Upshaw JE, Tuuri RE: A 14-year-old male with a 10-week history of headaches. Pediatr Ann 43:220, 222-223, 2014

16. Ellis MJ, Leiter J, Hall T, McDonald PJ, Sawyer S, Silver N, et al: Neuroimaging findings in pediatric sports-related concussion. J Neurosurg Pediatr 16:241-247, 2015

17. Eustace S, Toland J, Stack J: CT and MRI of arachnoid cyst with complicating intracystic and subdural haemorrhage. J Comput Assist Tomogr 16:995-997, 1992

18. Forbes JA, Zuckerman S, Abla AA, Mocco J, Bode K, Eads T: Biomechanics of subdural hemorrhage in American football: review of the literature in response to rise in incidence. Childs Nerv Syst 30:197-203, 2014

19. Forbes JA, Zuckerman SL, He L, McCalley E, Lee YM, Solomon GS, et al: Subdural hemorrhage in two high-school football players: post-injury helmet testing. Pediatr Neurosurg 49:43-49, 2013

20. Galassi E, Tognetti F, Gaist G, Fagioli L, Frank F, Frank G: CT scan and metrizamide CT cisternography in arachnoid cysts of the middle cranial fossa: classification and pathophysiological aspects. Surg Neurol 17:363-369, 1982

21. Gamradt SC, Brophy R, Barnes R, Birchansky S, Rodeo SA, Warren RF, et al: Incidental findings in cerebral imaging: arachnoid cyst in a professional football player. Clin J Sport Med 18:97-99, 2008

22. Gelabert-González M, Fernández-Villa J, Cutrín-Prieto J, Garcìa Allut A, Martínez-Rumbo R: Arachnoid cyst rupture with subdural hygroma: report of three cases and literature review. Childs Nerv Syst 18:609-613, 2002

23. Gupta R, Vaishya S, Mehta VS: Arachnoid cyst presenting as subdural hygroma. J Clin Neurosci 11:317-318, 2004

24. Hamada H, Hayashi N, Umemura K, Kurosaki K, Endo S: Middle cranial fossa arachnoid cyst presenting with subdural effusion and endoscopic detection of tear of the cyst-case report. Neurol Med Chir (Tokyo) 50:512-514, 2010

25. Harch PG, Andrews SR, Fogarty EF, Amen D, Pezzullo JC, Lucarini J, et al: A phase I study of low-pressure hyperbaric oxygen therapy for blast-induced post-concussion syndrome and post-traumatic stress disorder. J Neurotrauma 29:168185,2012

26. Hou K, Li CG, Zhang Y, Zhu BX: The surgical treatment of three young chronic subdural hematoma patients with different causes. J Korean Neurosurg Soc 55:218-221, 2014

27. Huang PP: Roller coaster headaches revisited. Surg Neurol 60:398-401, 2003

28. Işik HS, Yildiz Ö, Ceylan Y: Chronic subdural hematoma caused by soccer ball trauma associated with arachnoid cyst in childhood: Case report. J Neurol Sci (Turk) 28:398-401, 2011

29. Kaplan EL, Meier P: Nonparametric estimation from incomplete observations. J Am Stat Assoc 53:457-481, 1958

30. Kawanishi A, Nakayama M, Kadota K: Heading injury precipitating subdural hematoma associated with arachnoid cysts - two case reports. Neurol Med Chir (Tokyo) 39:231233, 1999

31. Kertmen H, Gürer B, Yilmaz ER, Sekerci Z: Chronic subdu- 
ral hematoma associated with an arachnoid cyst in a juvenile taekwondo athlete: a case report and review of the literature. Pediatr Neurosurg 48:55-58, 2012

32. Kontos AP, Elbin RJ, Schatz P, Covassin T, Henry L, Pardini $\mathrm{J}$, et al: A revised factor structure for the post-concussion symptom scale: baseline and postconcussion factors. Am J Sports Med 40:2375-2384, 2012

33. Kulali A, von Wild K: Post-traumatic subdural hygroma as a complication of arachnoid cysts of the middle fossa. Neurosurg Rev 12 (Suppl 1):508-513, 1989

34. LaCour F, Trevor R, Carey M: Arachnoid cyst and associated subdural hematoma. Observations on conventional roentgenographic and computerized tomographic diagnosis. Arch Neurol 35:84-89, 1978

35. Langlois JA, Rutland-Brown W, Wald MM: The epidemiology and impact of traumatic brain injury: a brief overview. J Head Trauma Rehabil 21:375-378, 2006

36. Lau BC, Collins MW, Lovell MR: Cutoff scores in neurocognitive testing and symptom clusters that predict protracted recovery from concussions in high school athletes. Neurosurgery 70:371-379, 2012

37. Liu Z, Xu P, Li Q, Liu H, Chen N, Xu J: Arachnoid cysts with subdural hematoma or intracystic hemorrhage in children. Pediatr Emerg Care 30:345-351, 2014

38. Longatti P, Marton E, Billeci D: Acetazolamide and corticosteroid therapy in complicated arachnoid cyst. Childs Nerv Syst 21:1061-1064, 2005

39. Lynch JM, Anderson M, Benton B, Green SS: The gaming of concussions: a unique intervention in postconcussion syndrome. J Athl Train 50:270-276, 2015

40. Maeda M, Kawamura Y, Handa Y, Kubota T, Ishii Y: Value of MR imaging in middle fossa arachnoid cyst with intracystic and subdural hematoma. Eur J Radiol 17:145-147, 1993

41. Maher CO, Garton HJ, Al-Holou WN, Trobe JD, Muraszko KM, Jackson EM: Management of subdural hygromas associated with arachnoid cysts. J Neurosurg Pediatr 12:434-443, 2013

42. McNeil SL, Spruill WA, Langley RL, Shuping JR, Leonard JR III: Multiple subdural hematomas associated with breakdancing. Ann Emerg Med 16:114-116, 1987

43. Meehan WP III, d'Hemecourt P, Comstock RD: High school concussions in the 2008-2009 academic year: mechanism, symptoms, and management. Am J Sports Med 38:24052409, 2010

44. Miele VJ, Bailes JE, Martin NA: Participation in contact or collision sports in athletes with epilepsy, genetic risk factors, structural brain lesions, or history of craniotomy. Neurosurg Focus 21(4):E9, 2006

45. Moher D, Liberati A, Tetzlaff J, Altman DG: Preferred reporting items for systematic reviews and meta-analyses: the PRISMA statement. J Clin Epidemiol 62:1006-1012, 2009

46. Morgan CD, Zuckerman SL, King LE, Beaird SE, Sills AK, Solomon GS: Post-concussion syndrome (PCS) in a youth population: defining the diagnostic value and cost-utility of brain imaging. Childs Nerv Syst 31:2305-2309, 2015

47. Mori K, Yamamoto T, Horinaka N, Maeda M: Arachnoid cyst is a risk factor for chronic subdural hematoma in juveniles: twelve cases of chronic subdural hematoma associated with arachnoid cyst. J Neurotrauma 19:10171027, 2002

48. Mori T, Fujimoto M, Sakae K, Sakakibara T, Shin H, Yamaki $\mathrm{T}$, et al: Disappearance of arachnoid cysts after head injury. Neurosurgery 36:938-942, 1995

49. Naidich TP, McLone DG, Radkowski MA: Intracranial arachnoid cysts. Pediatr Neurosci 12:112-122, 1985-1986

50. Ochi M, Morikawa M, Ogino A, Nagaoki K, Hayashi K: Supratentorial arachnoid cyst and associated subdural hematoma: neuroradiologic studies. Eur Radiol 6:640-644, 1996

51. Offiah C, St Clair Forbes W, Thorne J: Non-haemorrhagic subdural collection complicating rupture of a middle cranial fossa arachnoid cyst. Br J Radiol 79:79-82, 2006

52. Oliver LC: Primary arachnoid cysts: report of two cases. BMJ 1:1147-1149, 1958

53. Page A, Paxton RM, Mohan D: A reappraisal of the relationship between arachnoid cysts of the middle fossa and chronic subdural haematoma. J Neurol Neurosurg Psychiatry 50:1001-1007, 1987

54. Park HR, Lee KS, Bae HG: Chronic subdural hematoma after eccentric exercise using a vibrating belt machine. J Korean Neurosurg Soc 54:265-267, 2013

55. Park SH, Lee SH, Park J, Hwang JH, Hwang SK, Hamm IS: Chronic subdural hematoma preceded by traumatic subdural hygroma. J Clin Neurosci 15:868-872, 2008

56. Parsch CS, Krauss J, Hofmann E, Meixensberger J, Roosen $\mathrm{K}$ : Arachnoid cysts associated with subdural hematomas and hygromas: analysis of 16 cases, long-term follow-up, and review of the literature. Neurosurgery 40:483-490, 1997

57. Pascoe HM, Phal PM, King JA: Progressive post traumatic tearing of an arachnoid cyst membrane resulting in intracystic and subdural haemorrhage. J Clin Neurosci 22:897-899, 2015

58. Pillai P, Menon SK, Manjooran RP, Kariyattil R, Pillai AB, Panikar D: Temporal fossa arachnoid cyst presenting with bilateral subdural hematoma following trauma: two case reports. J Med Case Reports 3:53, 2009

59. Prabhu VC, Bailes JE: Chronic subdural hematoma complicating arachnoid cyst secondary to soccer-related head injury: case report. Neurosurgery 50:195-198, 2002

60. Pretorius PM, McAuley DJ: Something old, something new? Br J Radiol 78:1063-1064, 2005

61. Raveenthiran V, Reshma KB: Sixth cranial nerve palsy due to arachnoid cyst. J Pediatr Ophthalmol Strabismus 51:e58-e61, 2014

62. Robles LA, Hernandez V: Subdural and intracystic haematomas in an arachnoid cyst secondary to a boxing injury. Inj Extra 37:375-378, 2006

63. Rogers MA, Klug GL, Siu KH: Middle fossa arachnoid cysts in association with subdural haematomas. A review and recommendations for management. Br J Neurosurg 4:497-502, 1990

64. Santamarta D, Aguas J, Ferrer E: The natural history of arachnoid cysts: endoscopic and cine-mode MRI evidence of a slit-valve mechanism. Minim Invasive Neurosurg 38:133137,1995

65. Seddighi A, Seddighi AS, Baqdashti HR: Asymptomatic presentation of huge extradural hematoma in a patient with arachnoid cyst. Br J Neurosurg 26:917-918, 2012

66. Sener RN: Arachnoid cysts associated with post-traumatic and spontaneous rupture into the subdural space. Comput Med Imaging Graph 21:341-344, 1997

67. Silverberg ND, Gardner AJ, Brubacher JR, Panenka WJ, Li JJ, Iverson GL: Systematic review of multivariable prognostic models for mild traumatic brain injury. J Neurotrauma 32:517-526, 2015

68. Takizawa K, Sorimachi T, Honda Y, Ishizaka H, Baba T, Osada T, et al: Chronic subdural hematomas associated with arachnoid cysts: significance in young patients with chronic subdural hematomas. Neurol Med Chir (Tokyo) 55:727734,2015

69. Tator $\mathrm{CH}$, Davis $\mathrm{H}$ : The postconcussion syndrome in sports and recreation: clinical features and demography in 138 athletes. Neurosurgery 75 (Suppl 4):S106-S112, 2014

70. Tsitsopoulos PP, Pantazis GC, Syrmou EC, Tsitsopoulos PD: Intracranial arachnoid cyst associated with traumatic intracystic hemorrhage and subdural haematoma. Hippokratia 12:53-55, 2008

71. Tsuzuki N, Katoh H, Ohtani N: Chronic subdural hematoma complicating arachnoid cyst secondary to soccer-related head injury: case report. Neurosurgery 53:242-243, 2003 
72. Türkoğlu E, Serbes G, Sanli M, Sari O, Sekerci Z: Chronic subdural hematoma in capoeira sport. Turk Neurosurg 18:39-41, 2008

73. Ulmer S, Engellandt K, Stiller U, Nabavi A, Jansen O, Mehdorn MH: Chronic subdural hemorrhage into a giant arachnoidal cyst (Galassi classification type III). J Comput Assist Tomogr 26:647-653, 2002

74. Varma TR, Sedzimir CB, Miles JB: Post-traumatic complications of arachnoid cysts and temporal lobe agenesis. J Neurol Neurosurg Psychiatry 44:29-34, 1981

75. Vigil DV, DiFiori JP, Puffer JC, Peacock WJ: Arachnoid cyst and subdural hygroma in a high school football player. Clin $\mathbf{J}$ Sport Med 8:234-237, 1998

76. Weber F, Knopf $\mathrm{H}$ : Incidental findings in magnetic resonance imaging of the brains of healthy young men. J Neurol Sci 240:81-84, 2006

77. Weinberg PE, Flom RA: Intracranial subarachnoid cysts. Radiology 106:329-333, 1973

78. Wester K: Gender distribution and sidedness of middle fossa arachnoid cysts: a review of cases diagnosed with computed imaging. Neurosurgery 31:940-944, 1992

79. Wester K, Helland CA: How often do chronic extra-cerebral haematomas occur in patients with intracranial arachnoid cysts? J Neurol Neurosurg Psychiatry 79:72-75, 2008

80. Yokoyama K, Tonami N, Kimura M, Kinoshita A, Aburano T, Hisada K: Scintigraphic demonstration of intracranial communication between arachnoid cyst and associated subdural hematoma. Clin Nucl Med 14:350-353, 1989

81. Zeng T, Shi SS, Lin YF: Chronic subdural hematoma associated with sylvian arachnoid cyst in juvenile athletes: report of two cases and literature review. Chin J Traumatol 14:174177,2011

82. Zhang H, Zhang JM, Chen G: Chronic subdural hematoma associated with arachnoid cyst: report of two cases. Chin Med J (Engl) 120:2339-2340, 2007

83. Zheng SP, Li GP, You C: Chronic subdural hematoma associated with arachnoid cysts in young people. Neurosurg $\mathbf{Q}$ 23:258-261, 2013

84. Zuckerman SL, Kuhn A, Dewan MC, Morone PJ, Forbes JA,
Solomon GS, et al: Structural brain injury in sports-related concussion. Neurosurg Focus 33(6):E6, 1-12, 2012

85. Zuckerman SL, Morgan CD, Burks S, Forbes JA, Chambless LB, Solomon GS, et al: Functional and structural traumatic brain injury in equestrian sports: a review of the literature. World Neurosurg 83:1098-1113, 2015

\section{Disclosures}

The authors report the following. Dr. Solomon receives consulting fees from the Tennessee Titans (NFL), the Nashville Predators (NHL), and the athletic departments for several universities. In addition he is a member of the ImPACT advisory board and receives reimbursement for expenses to board meetings, and also receives royalties from book sales. Dr. Sills is a consulting physician to the Nashville Predators (uncompensated) and also serves as an unaffiliated neurotrauma consultant for the NFL. Dr. Bonfield serves as an unaffiliated neurotrauma consultant for the NFL.

\section{Author Contributions}

Conception and design: Zuckerman, Solomon, Sills, Bonfield. Acquisition of data: Prather, Yengo-Kahn. Analysis and interpretation of data: all authors. Drafting the article: Zuckerman. Critically revising the article: all authors. Reviewed submitted version of manuscript: Zuckerman, Solomon, Sills, Bonfield. Approved the final version of the manuscript on behalf of all authors: Zuckerman. Statistical analysis: Zuckerman. Administrative/technical/ material support: Solomon, Sills, Bonfield. Study supervision: Solomon, Sills, Bonfield.

\section{Correspondence}

Scott L. Zuckerman, Department of Neurological Surgery, Vanderbilt University School of Medicine, 1211 Medical Center Dr., Medical Center North T-4224, Nashville, TN 37212. email: scott.zuckerman@vanderbilt.edu. 